\title{
Relationship between glycated haemoglobin and fasting plasma glucose among diabetic out-patients at the University Teaching Hospital, Lusaka, Zambia
}

\author{
EMMANUEL M. MUSENGE ${ }^{*}$, ALEXEY MANANKOV ${ }^{1}$, CHARLES MICHELO $^{2}$ and BOYD MUDENDA ${ }^{2}$ \\ ${ }^{1}$ Department of Physiological Sciences, School of Medicine, University of Zambia, P.O. Box 50110, Ridgeway \\ Campus, Lusaka, Zambia \\ ${ }^{2}$ Department of Public Health, School of Medicine, University of Zambia, Ridgeway Campus, Lusaka, Zambia
}

\begin{abstract}
Background: Glycated haemoglobin $\left(\mathrm{HbA}_{1 \mathrm{c}}\right)$ measurement provides an accurate result of glycaemic levels from blood drawn at any time of day without reference to prandial state. We established the relationship between $\mathrm{HbA}_{1 c}$ and fasting plasma glucose (FPG) in diabetic out-patients among diabetic outpatients in Lusaka, Zambia.

Methods: This cross-sectional study was carried out at the University Teaching Hospital diabetic clinic, Lusaka, Zambia. A total sample of 198 consenting participants was selected randomly from diabetic outpatients between September and December 2013. A structured interview schedule was used to capture data on socio-demographics and laboratory examination results. The Pearson's correlation coefficient, Student's t-test and Paired Samples t-test were used for data analysis.

Results: A total of 198 patients (mean age+SD=53.19 \pm 13.32 years) were involved in the study. Majority (60.10\%) of the patients were females while 39.90 per cent were males. The mean \pm SD of FPG of the patients slightly increased from the previous $10.75 \pm 7.78 \mathrm{mmo} / \mathrm{L}$ to the current $11.09 \pm 6.23 \mathrm{mmo} / \mathrm{L}(p=$ 0.592). The mean $\pm \mathrm{SD}$ of $\mathrm{HbA}_{1 c}$ of the patients was $54.77 \pm 17.12 \mathrm{mmol} / \mathrm{mol}$. There was a statistically significant weak and moderate positive correlation between $\mathrm{HbA}_{1 c}$ and the previous and current FPG $(r=$ $0.282, P=0.001$ and $(r=0.385, p=0.001)$, respectively. However, there was a statistically significant but weak negative correlation between $\mathrm{HbA}_{1 c}$ and age $(r=-0.163, p=0.023)$.

Conclusion: We found evidence of an association between $\mathrm{HbA}_{1 \mathrm{c}}$ and FPG proposing that as the FPG levels increase, the $\mathrm{HbA}_{1 \mathrm{c}}$ levels also increase in a predictable way. There is need to sensitise more especially the major stakeholders in the management of diabetes mellitus to consider FPG as an alternative in glycaemic control monitoring in the absence of $\mathrm{HbA}_{1 \mathrm{c}}$.
\end{abstract}

Keywords: Diabetes mellitus, glycated haemoglobin, fasting plasma glucose, Zambia

\section{Introduction}

Diabetes mellitus (DM) is the most common metabolic disease (Haddadinezhad \& Chazaleh, 2010) and is characterised by hyperglycaemia. The hyperglycaemia sufficient to cause pathological and functional changes in DM is frequently present for a long time before the complications appear (Agarwal et al., 2013). The management of DM necessitates an accurate assessment of glycaemic control (Raja et al., 2013). Glycaemic control monitoring can be achieved by $\mathrm{HbA}_{1 \mathrm{c}}$ and FPG among other tests. However, glycaemic control in diabetic patients can be best ascertained by $\mathrm{HbA}_{1 \mathrm{c}}$ levels (Kilpatrick et al., 2009).

Glycated haemoglobin is formed by the non-enzymatic glycation of free amino groups at the $\mathrm{N}$-terminus of the $\beta$-chain of $\mathrm{HbA}_{1 \mathrm{c}}$ by adult $\mathrm{Hb}$ 's exposure to plasma glucose (Kilpatrick et al., 2009). $\mathrm{HbA}_{1 \mathrm{c}}$ is a gold standard in analysis of patients' glycaemic control status, and is essential to ensure the optimal care of diabetic patients (Ghazanfari et al., 2010; ADA, 2010). Because red blood cells (RBCs) in the human body survive for 8-12 weeks before renewal, measuring $\mathrm{HbA}_{1 \mathrm{c}} \mathrm{Can}$ be used to reflect average blood glucose levels over that duration, providing a useful longer-term gauge of glycaemic control (Roszyk et al., 2007). As the average amount of plasma glucose

*Correspondence E-mail: emmanuel.musenge@unza.zm or emmasenge@yahoo.com 
increases, the fraction of $\mathrm{HbA}_{1 c}$ increases in a predictable way (Roszyk et al., 2007). However, the major proportion of its value is weighted toward the most recent two to four weeks (Sidorenkov et al., 2011).

The long-term assessment of blood glucose is advantageous because it eliminates the large fluctuations that occur daily in blood glucose concentrations. In contrast to glucose measurements, $\mathrm{HbA}_{1 \mathrm{c}}$ also provides an accurate result from blood drawn at any time of day without reference to prandial state (Burtis et al., 2006). In general, the frequency of plasma glucose testing depends on the type of DM the patient has and the treatment plan. However, the $\mathrm{HbA}_{1 \mathrm{c}}$ test should be done approximately every three months in uncontrolled or at least twice a year in well-controlled diabetic patients. The normal FPG levels are between 4.1 to $5.9 \mathrm{mmol} / \mathrm{L}$ when using the $A B X$ Pentra 400 Clinical Chemistry Analyser (Burtis et al., 2006). Also, the therapeutic objective of $\mathrm{HbA}_{1 \mathrm{c}}$ has been to obtain values $\leq 48 \mathrm{mmol} / \mathrm{mol}$ (IDF, 2009). However, patients with an $\mathrm{HbA}_{1 \mathrm{c}} \geq 48 \mathrm{mmol} / \mathrm{mol}$ have an increased mortality rate (Roszyk et al., 2007). In addition, a 1 per cent change in $\mathrm{HbA}_{1 \mathrm{c}}$ is equivalent to an approximately $1.94 \mathrm{mmol} / \mathrm{L}$ (Ghazanfari et al., 2010) and $1.98 \mathrm{mmol} / \mathrm{L}$ (Saiedullah et al., 2011) changes in mean plasma glucose (MPG). Thus, each 1 per cent reduction in the value of $\mathrm{HbA}_{1 \mathrm{c}}$, results in risk of microvascular complications reduction by 40\% (Ghazanfari et al., 2010).

The combined use of FPG and $\mathrm{HbA}_{1 \mathrm{c}}$ levels predicts the progression to DM in individuals with no apparent risk. In particular, the combination is recommended for individuals with a FPG $\geq 5.55 \mathrm{mmol} / \mathrm{L}$ (Inoue et al., 2007). Most countries in the world are using $\mathrm{HbA}_{1 \mathrm{c}}$ for both diagnosis and long-term monitoring of DM to establish control status. However, due to the high cost, $\mathrm{HbA}_{1 c}$ is limitedly used in many developing countries (Wiwanitkit, 2011) including Zambia. The old classical approach of FPG determination is still the standard method in those countries.

Furthermore, many studies (Rohlfing et al., 2002; Kaur et al., 2014; Hossain et al., 2012; Haddadinezhad \& Ghazaleh, 2010) have shown a relationship between $\mathrm{HbA}_{1 \mathrm{c}}$ and FPG and most clinicians would want to use the $\mathrm{HbA}_{1 c}$ to monitor glycaemic control among their DM patients. Although, there is so much emphasis on $\mathrm{HbA}_{1 c}$ as the best method to monitor glycaemic control, regular checking and good record keeping of FPG levels can be an alternative to those DM patients without access to $\mathrm{HbA}_{1 c}$ measurement facilities. Therefore, the main objective of the study was to establish the relationship between $\mathrm{HbA}_{1 c}$ and FPG in diabetic out-patients at the University Teaching Hospital (UTH), Lusaka, Zambia. The study will help diabetic patients and their healthcare providers set day-to-day targets for plasma glucose to achieve specific $\mathrm{HbA}_{1 c}$ goals.

\section{Materials and Methods}

\section{Study design}

This cross-sectional study was carried out at UTH Diabetic Clinic, Lusaka, Zambia. The UTH has a bed capacity of 1800 and serves as the main tertiary referral hospital for Zambia (Lumba, 2014). The clinic manages patients with numerous diseases, including DM. The patients visit the clinic at appointed times advised by the medical officers for review and continuous monitoring their DM.

All the confirmed diabetic out-patients for at least two years and aged 15 years and above were included in the study. This is because patients with chronic illnesses tend to become noncompliant to medication with time. Also this age was chosen because the study was conducted at an adult clinic. Patients who were recruited in the previous month(s) were excluded from the study. This was to avoid studying the same patients over and over. A simple random sampling method was used in this study. The patients were selected consecutively from September to December, 2013 based on the daily sampling frame to avoid sampling bias. The sample size was calculated based on the 360 diabetic out-patients who passed through the diabetic clinic during 
the period of data collection. Based on Krejcie \& Morgan's (1970) formula for calculating sample size of a finite population, a sample size of 186 participants was achieved.

\section{Data collection}

A structured interview schedule was used to capture data on socio-demographic characteristics and laboratory examination results. The interview schedule was developed based on the World Health Organization (WHO) stepwise survey (STEPS) instrument, version three (WHO, 2007). The same instruments were used on all the patients to ensure reliability and validity. The data on socio-demographic characteristics, FPG and $\mathrm{HbA}_{1 c}$ were obtained by interview, review of medical records and laboratory measurements. Collecting blood for $\mathrm{HbA}_{1 \mathrm{c}}$ and FPG is part of the routine for these nurses. However, they were given a two-day orientation on how to use the data collection tool.

\section{Laboratory examination}

The quantitative determination of $\mathrm{HbA}_{1 \mathrm{c}}$ level in the collected blood from the diabetic patients was carried out by the immunoturbidimetry method using the ABX Pentra 400 Automated Clinical Chemistry Analyser (HORIBA ABX SAS, 34184 Montpellier, France). The technique has been certified by the National Glycohaemoglobin Standardisation Program (NGSP) of Australia (Burtis et al., 2006). The FPG was measured by the enzymatic determination of glucose using the Trinder method with the same analyser (Arvind et al, 2004; Rvind, 2009).

\section{Data analysis}

Statistical analyses were carried out using IBM ${ }^{\circledast}$ SPSS $^{\circledast}$ Statistics for Windows Version 20.0 (IBM Corp. Armonk, NY, USA). The Pearson's correlation coefficient and Student's t-test were used for bivariate analyses. The paired samples t-test was used for repeated measures of FPG to see whether there was a difference between the means. Statistical significance was considered at a $p$-value of $<0.05$.

\section{Ethical considerations}

This study was approved by the University of Zambia Biomedical Research Ethics Committee (Reference number 005-07-13). The patients who were willing to participate in the study were asked to give informed and written consent.

\section{Results}

\section{Participants and distribution}

A total of 198 out-patients were involved in the study. The mean \pm SD of age of the total study patients were $53.19 \pm 13.32$ ranging from 19 to 82 years. Of the total patients, 79 (39.90\%) were males and $119(60.10 \%)$ were females. The mean \pm SD of FPG of the patients for the previous three months and current was higher $(10.75 \pm 7.78 \mathrm{mmo} / \mathrm{L}$ and $11.09 \pm 6.23 \mathrm{mmo} / \mathrm{L})$ than the normal $(4.1-$ $5.9 \mathrm{mmol} / \mathrm{L})$. Using the paired samples t-test, there was a very slight increase in the FPG from the previous $(10.75 \pm 7.78 \mathrm{mmo} / \mathrm{L})$ to the current $(11.09 \pm 6.23 \mathrm{mmo} / \mathrm{L})$. However, the difference was not statistically significant $(p=0.592)$. The mean \pm SD of $\mathrm{HbA}_{1 c}$ of the patients was $54.77 \pm 17.12$ $\mathrm{mmol} / \mathrm{mol}$.

\section{Comparison of the glycaemic parameter levels and age}

The mean \pm SD levels of $\mathrm{HbA}_{1 \mathrm{c}}$, current FPG and age were higher in females than in males except for the previous FPG (Table 1). However, there was no significant gender difference for the glycaemic parameter levels except for age when the student's t-test was used (Table 1). 
Table 1: Comparison of the glycaemic parameter levels and age in males and females $(n=198)$

\begin{tabular}{llll}
\hline Parameter & Male & Female & P-value* \\
\cline { 2 - 3 } & $\mathrm{N}($ Mean $\pm \mathrm{SD})$ & $\mathrm{N}($ Mean+SD $)$ & \\
\hline $\mathrm{HbA}_{1 \mathrm{c}}(\mathrm{mmol} / \mathrm{mol})$ & $76(53.19 \pm 15.52)$ & $118(55.80+18.05)$ & 0.301 \\
Previous FPG $(\mathrm{mmol} / \mathrm{L})$ & $76(11.50 \pm 10.60)$ & $117(10.20 \pm 5.12)$ & 0.258 \\
Current FPG $(\mathrm{mmol} / \mathrm{L})$ & $77(10.50 \pm 7.35)$ & $118(11.30 \pm 5.36)$ & 0.377 \\
Age $($ Years $)$ & $79(50.84 \pm 15.32)$ & $119(54.75 \pm 11.61)$ & 0.043 \\
\hline
\end{tabular}

Key: $N=$ number of patients; $S D=$ Standard deviation; * = significant $P$-value at $p<0.05$

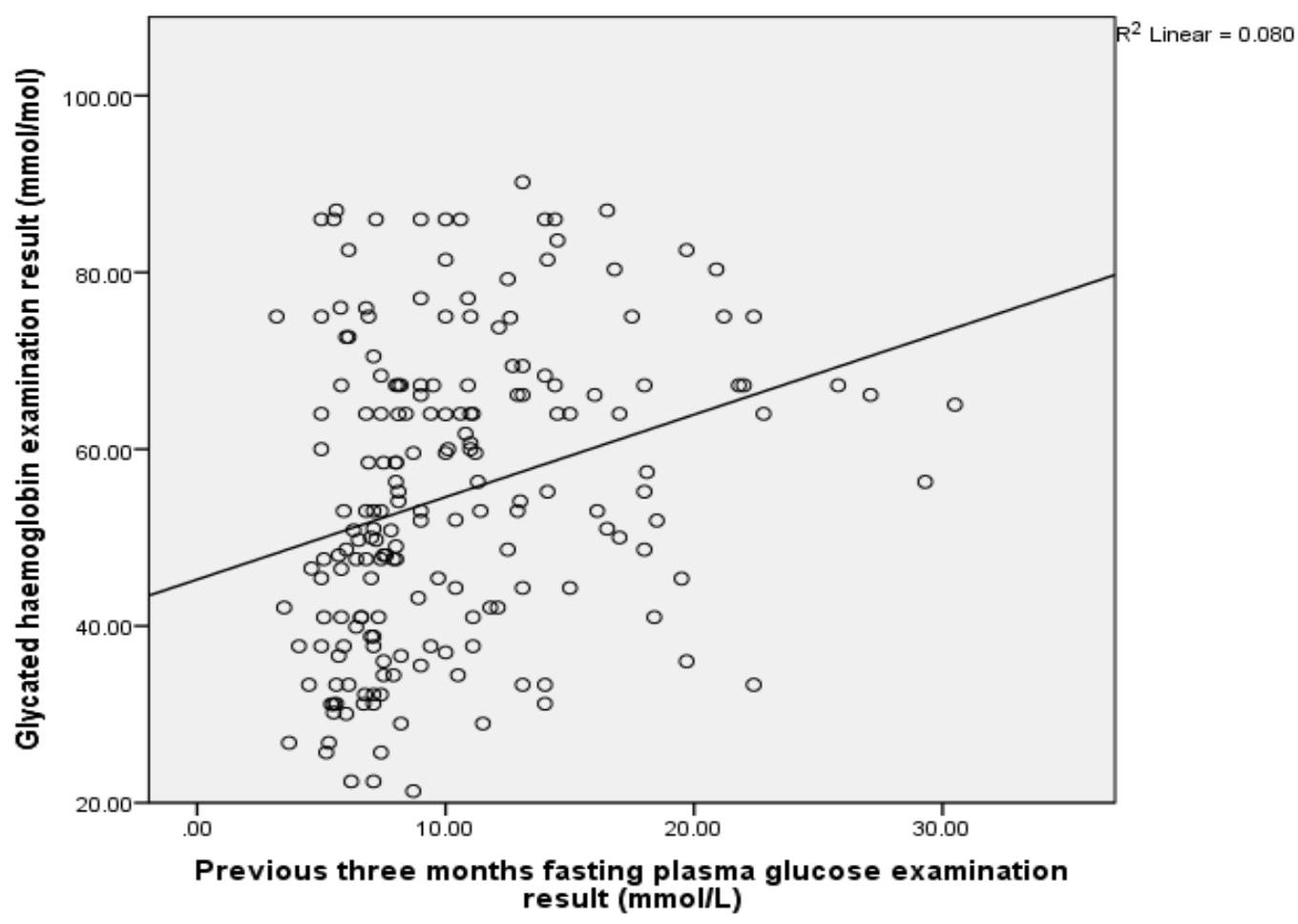

Figure 1: A scatter-plot of $\mathrm{HbA}_{1 \mathrm{c}}$ versus previous three months FPG $(\mathrm{p}<0.01)$

\section{Relationship between HbA1c versus FPG and age}

The Pearson's correlation coefficient test was run to establish the relationship between $\mathrm{HbA}_{1}$, FPG and age. There was a statistically significant but weak positive correlation between $\mathrm{HbA}_{1 \mathrm{c}}$ mean $\pm S D(54.77 \pm 17.12 \mathrm{mmol} / \mathrm{mol})$ and the previous FPG mean $\pm S D(10.75 \pm 7.78 \mathrm{mmo} / \mathrm{L})(r=0.282$, $P=0.001)$ (Figure 1). However, there was a statistically significant moderate positive correlation between $\mathrm{HbA}_{1 \mathrm{C}}(54.77 \pm 17.12 \mathrm{mmol} / \mathrm{mol})$ and the current FPG $(11.09 \pm 6.23 \mathrm{mmo} / \mathrm{L})(r=0.385, P=$ 0.001) (Figure 2). There was a statistically significant but weak negative correlation between $\mathrm{HbA}_{1 \mathrm{c}}$ mean $\pm \mathrm{SD}(54.77 \pm 17.12 \mathrm{mmol} / \mathrm{mol})$ and the age mean $\pm \mathrm{SD}(53.19 \pm 13.32$ years $)(r=-0.163, P=$ 0.023 ) (Figure 3). 


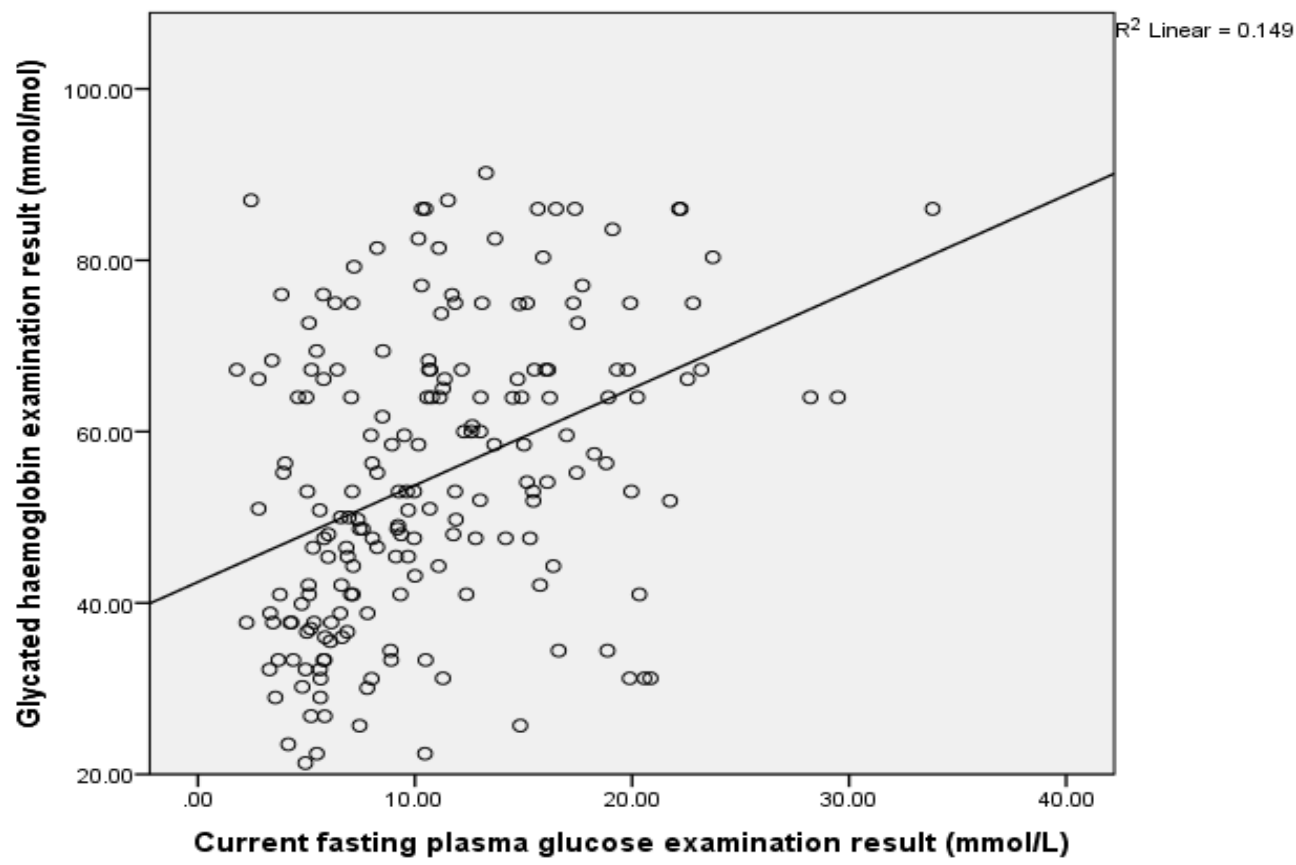

Figure 2: A scatter-plot of $\mathrm{HbA}_{1 \mathrm{c}}$ versus current FPG $(\mathrm{p}<0.01)$

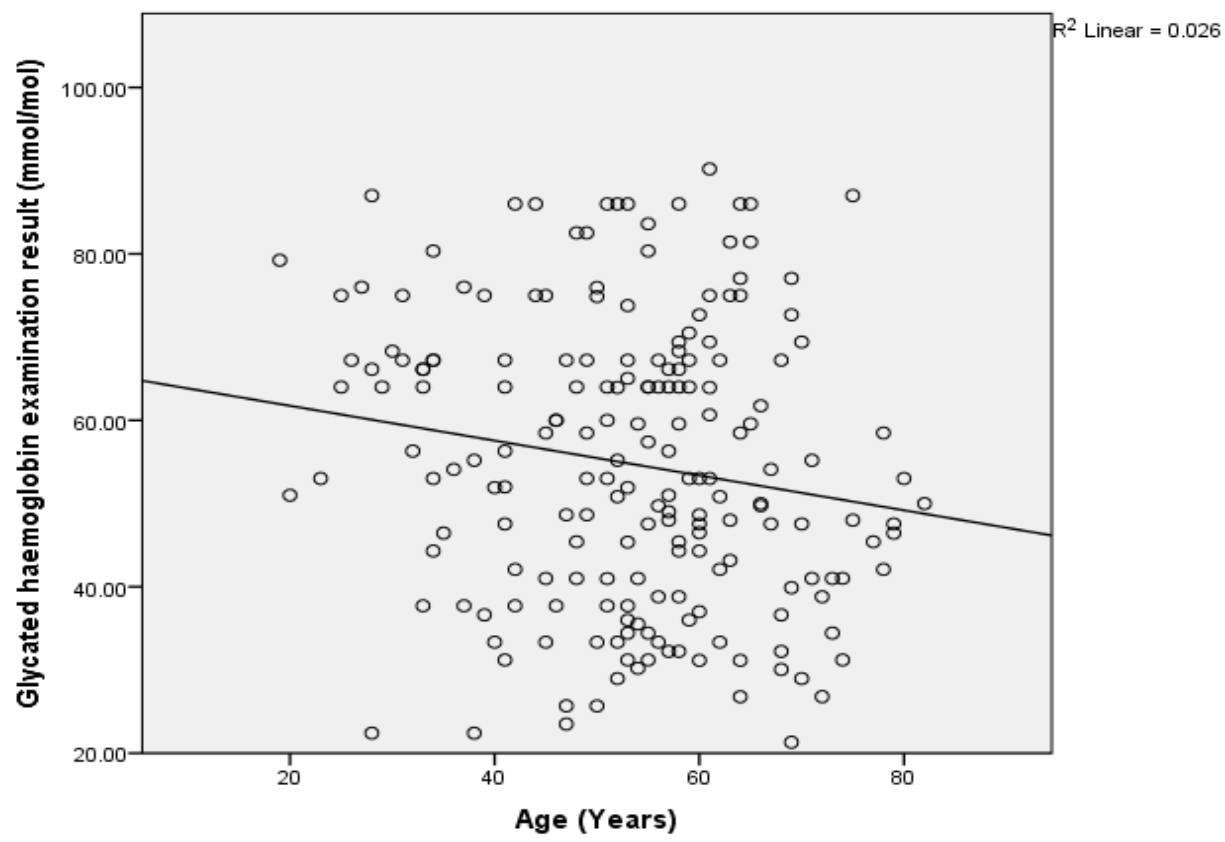

Figure 3: A scatter-plot of $\mathrm{HbA}_{1 c}$ versus age $(\mathrm{p}<0.01)$

\section{Discussion}

The $\mathrm{HbA}_{1 \mathrm{c}}$ is a product of non-enzymatic reaction between glucose and free amino groups of $\mathrm{Hb}$ involving lots of other proteins, too and it is the principal mechanism through which glucotoxicity 
is formed. $\mathrm{HbA}_{1 \mathrm{c}}$ measurement is now considered as the best index for the control of diabetes as well as for preventing its complications (Saiedullah et al., 2011). However, $\mathrm{HbA}_{1 c}$ test is subject to certain limitations in conditions that affect RBC turnover. Haemoglobin variants must be considered, particularly when the $\mathrm{HbA}_{1 c}$ result does not correlate with the patient's clinical situation (Sacks et al., 2002) and this makes the relationship between $\mathrm{HbA}_{1 \mathrm{C}}$ and FPG complex.

The current study revealed that the FPG of the patients for the previous three months and current was higher than the normal; and there was a slight increase in the FPG from the previous to the current which difference was not statistically significant. The $\mathrm{HbA}_{1 c}$ of the patients was also higher than the normal. Similarly, Haddadinezhad \& Ghazaleh (2010) and Saiedullah et al. (2011) reported a higher than normal $\mathrm{HbA}_{1 \mathrm{c}}$ and FPG of the patients.

This study revealed a weak negative correlation between $\mathrm{HbA}_{1 \mathrm{c}}$ and age. On the other hand, Rohlfing et al. (2002), Kaur et al. (2014) and Saiedullah et al. (2011) reported a higher correlation between $\mathrm{HbA}_{1 \mathrm{c}}$ and FPG. The correlation was strongest in the age group below 30 years but the difference was insignificant between males and females (Haddadinezhad \& Ghazaheh, 2010; Mo et al., 2013; Liang et al., 2010; Rajal Reddy et al., 2013; Kaur et al., 2014). In addition, some studies reported strong positive correlation between $\mathrm{HbA}_{1 \mathrm{c}}$ and FPG (DCCT/NGSP, 2005; Pani et al., 2008; Liang et al., 2010;). However, Wiener \& Roberts (1999) and Mo et al. (2013) reported a non-significant correlation between age and $\mathrm{HbA}_{1 c}$. It appears that $\mathrm{HbA}_{1 c}$-age represents only the metabolic status (Turk et al., 1998). The prevalence of such abnormality would be expected to be greater amongst older subjects, falsely suggesting a correlation between $\mathrm{HbA}_{1 c}$ and age (Wiener \& Roberts, 1999). The combined screening with FPG and $\mathrm{HbA}_{1 c}$ may identify older adults at very high risk for diabetes when FPG and $\mathrm{HbA}_{1 c}$ are considered together. Thus, the selection of subjects may be the key to the differences in the influence of age on $\mathrm{HbA}_{1 \mathrm{c}}$ (Wiener \& Roberts, 1999).

Most importantly, the current study revealed a weak and moderate positive correlation between $\mathrm{HbA}_{1 \mathrm{c}}$ and previous and current FPG. The results are similar to those by Hossain et al. (2012), Haddadinezhad \& Ghazaleh (2010) and Wiwanitkit (2012), who reported moderate correlations between $\mathrm{HbA}_{1 \mathrm{c}}$ and FPG. The poor correlation might be due to the high prevalence of $\mathrm{Hb}$ disorder in the study setting. Thus, FPG might not be used to imply $\mathrm{HbA}_{1 \mathrm{c}}$ in the areas with the background of endemic Hb disorder (Wiwanitkit, 2012).

Silverman et al. (2008) and Haddadinezhad \& Ghazaleh (2010) reported a moderate to strong positive correlation between $\mathrm{HbA}_{1 c}$ levels and FPG. Several studies have revealed a strong positive correlation between $\mathrm{HbA}_{1 c}$ and FPG (Rohlfing et al., 2002; Liang et al., 2010; Bozkaya et al., 2010; Raja et al., 2013; Lipska et al. 2013; Kaur et al. 2014). This is because the level of $\mathrm{HbA}_{1 \mathrm{c}}$ is proportional to the level of glucose in the blood and normal levels of glucose produce a normal amount of $\mathrm{HbA}_{1 \mathrm{c}}$. Thus, as the average amount of plasma glucose increases, the fraction of $\mathrm{HbA}_{1 \mathrm{c}}$ increases in a predictable way and this serves as a marker for average blood glucose levels over the previous 8 to 12 weeks prior to the measurement (Roszyk et al., 2007). It is important to note that FPG test ascertains the glucose levels for the past few days but since blood glucose levels fluctuate throughout the day, glucose records are imperfect indicators of changes in the body due to hyperglycaemia. However, this does not mean that FPG cannot be used among DM patients who do not have access to $\mathrm{HbA}_{1 \mathrm{c}}$ measurement facilities.

There is an increase in the use of $\mathrm{HbA}_{1 c}$ to monitor long-term glycaemic control in diabetic patients (Rohlfing et al., 2002) as there is a strongly correlation between $\mathrm{HbA}_{1 c}$ with adverse outcome risks. The addition of elevated $\mathrm{HbA}_{1 c}$ to the model with raised FPG resulted in improved discrimination and calibration. In particular, the combination is recommended for individuals with a $\mathrm{FPG}>$ or $=5.55 \mathrm{mmol} / \mathrm{L}$ (Kazuo et al., 2007).

The level of $\mathrm{HbA}_{1 c}$ at any point in time is contributed to by all circulating RBCs, from the oldest (120 days old) to the youngest (NGSP, 2010). However, $\mathrm{HbA}_{1 \mathrm{c}}$ is a "weighted" average of blood glucose levels during the preceding 120 days, meaning that glucose levels in the preceding 
30 days contribute substantially more to the level of $\mathrm{HbA}_{1 \mathrm{c}}$ than do glucose levels 90-120 days earlier. This is supported by data from actual practice showing that $\mathrm{HbA}_{1 c}$ level improved significantly already after 20 days since glucose-lowering treatment intensification (Sidorenkov et al., 2011). This explains why the level of $\mathrm{HbA}_{1 c}$ can increase or decrease relatively quickly with large changes in plasma glucose; it does not take 120 days to detect a clinically meaningful change in $\mathrm{HbA}_{1 c}$ after a change in mean plasma glucose (Rohlfing et al., 2002; NGSP, 2010). Thus, calculated $\mathrm{HbA}_{1 \mathrm{c}}$ levels can be used with regular check-ups of FPG and $\mathrm{HbA}_{1 c}$ levels in diabetic patients at lesser cost (Manjunatha et al., 2011).

The association between the FPG and $\mathrm{HbA}_{1 c}$ level depends on the extent of glycaemic control. A clear understanding of the relationship between $\mathrm{HbA}_{1 \mathrm{c}}$ and FPG is necessary for setting appropriate day-to-day FPG testing goals with the expectation of achieving specific $\mathrm{HbA}_{1 \mathrm{c}}$ targets. There is need for patients and healthcare providers to include $\mathrm{HbA}_{1 \mathrm{c}}$ in the monitoring of diabetic out-patients to determine the effectiveness of glycaemic control measures. As long as the patients and healthcare providers continue to use plasma glucose tests alone, which fluctuate daily, it will be difficult to monitor glycaemic control adequately.

This study had limitations such as the time between the previous and current estimation of FPG was not the same for all patients. Some patients had their previous FPG reading taken four to six months prior to the study. Also, the establishment of the associated between $\mathrm{HbA}_{1 c}$ and FPG did not take into consideration the confounding factors. Furthermore, this study was carried out on a finite study population illustrated by the fact that only the participants who visited the UTH diabetic clinic during the period of data collection were included in the sample. Since the data on medical records of the diabetic patients at the clinic were incomplete; it was difficult to capture the previous FPG for some patients.

In conclusion, this study showed an association between $\mathrm{HbA}_{1 \mathrm{c}}$ and FPG suggesting that the level of the former is directly proportionate to the level of the later. Therefore, normal levels of FPG produce a normal amount of $\mathrm{HbA}_{1 c}$ and vice versa. The study will enable health care providers and DM patients to review the monitoring of glycaemic control by not only emphasising on $\mathrm{HbA}_{1 \mathrm{c}}$ even if it is not possible but to look at FPG as an alternative. This will be achieved through sensitisation especially among the major stakeholders in the management of diabetes mellitus.

\section{Competing interests}

The authors declare no competing interests.

\section{Authors' contributions}

EMM conceived the study. EMM, AM and CM designed the study. EMM collected and analysed the data and wrote the manuscript. AM, BM and CM supervised the whole study process, including the writing of the manuscript. All the authors read and approved the final manuscript. All the authors contributed equally and as stated in the manuscript.

\section{Acknowledgments}

We wish to express our gratitude to the staff of the departments of Physiological Sciences, Public Health and Internal Medicine of the University of Zambia for their contribution, the UTH management and staff in Diabetic Clinic and clinical chemistry laboratories for the facilities and support, and the Southern Africa Consortium for Research Excellence for guidance on data analysis. Finally, special thanks also go to the research assistants and the participants for their assistance and cooperation during the study. 


\section{References}

ADA (2010) Standards of Medical Care in Diabetes 2010. Diabetes Care 33, S11-S61.

Agarwal, N., Joshi, S., Deshpande, V.K. \& Biswas, D.A. (2013) Correlation between glycated haemoglobin and glucose testing for diabetes mellitus screening. Indian Journal of Medical Sciences 67, 149-154.

Burtis, C.A., Ashood, E.R. \& Burns, D.E. ed. (2006) Sacks, D.B., Carbohydrates, TIETZ Textbook of Clinical Chemistry and Molecular Diagnostics $4^{\text {th }}$ ed. St. Louis: Elseviers Saunders, 884.

Liang, C., Tsan, K., Ma, S., Chow, S., Wu, C. (2010) The relationship between fasting glucose and HbA1c among customers of health examination services. Formos Journal of Endocrinology and Metabolism 1, 9-13.

DCCT/NGSP (2005) Determination of reference intervals of $\mathrm{HbA}_{1 \mathrm{c}}$ and $\mathrm{HbA}_{1 \mathrm{c}}$ (IFCC) in adults. Journal of the Medical Association of Thailand 88, 810-816.

Ghazanfari, Z., NIknami, S., Ghofranipour, F., Larijani, B., Agha-Alinejad, H. \& Montazeri, A. (2010) Determinants of glycemic control in female diabetic patients: a study from Iran. Lipids in Health and Disease 9: 83

Haddadinezhad, S. \& Ghazaleh, N. (2010) Relationship of fasting and post prandial and plasma glucose with HbA1c in diabetes. International Journal of Diabetes in Developing Countries. 30 (1), 0973-3930.60002.

Hossain, T., Latif, Z.A. \& Sarkar, A.A. (2012) Relationship of HbA1c with fasting and plasma glucose 2 hours after oral glucose load in non-diabetic and newly diagnosed pre-diabetic and diabetic patients. Birdem Medical Journal 2(2), 81-83.

Inoue, K., Matsumoto, M. \& Kobayashi, Y. (2007) The combination of fasting plasma glucose and glycosylated haemoglobin predicts type 2 diabetes in Japanese workers. Diabetes Research and Clinical Practice 77, 451-458.

Kaur, V., Minni, V., Brinder, C., Amandeep, K., Kamaljit, S. (2014) To study the correlation between glycated hemoglobin and fasting/random blood sugar levels for the screening of diabetes mellitus. Journal of Advance Researches in Biological Sciences. 6, 21-25.

Kilpatrick, E.S., Bloomgarden, Z.T. \& Zimmet, P.Z. (2009) Is haemoglobin A1c a step forward for diagnosing diabetes? BMJ 339, 4432.

Krejcie, R.V. \& Morgan, D.W. (1970) Determining sample size for research activities. Educational and Psychological Measurements 30, 607-610.

Lipska, K.J., Inzucchi, S.E., Van Ness, P.H., Gill, T.M., Kanaya, A., Strotmeyer, E.S., Koster, A., Johnson, K.C., Goodpaster, B.H., Harris, T., De Rekeneire, N.; Health ABC Study. (2013) Elevated $\mathrm{HbA}_{1 \mathrm{c}}$ and fasting plasma glucose in predicting diabetes incidence among older adults. Diabetes Care 36, 3923.

Manjunatha, G.B.K., Bhavna, N., Sarsina, D.E.O., Sathisha, T.G., Sweta, S. \& Devaki, R.N. (2011) Relation of calculated $\mathrm{HbA}_{1 c}$ with fasting plasma glucose and duration of diabetes. International Journal of Applied Biology and Pharmaceutical Technology 2, 61.

Mo, M., Zhong, W., Zhao, G., Ruan, Y., Zhang, H., Shi, L., Lu, D., Yang, Q., Li, Y., Jiang, Q., Li, R. \& $\mathrm{Xu}, \mathrm{W}$. (2013) Combining glycosylated hemoglobin $A_{1 c}$ and fasting plasma glucose for diagnosis of type 2 diabetes in Chinese adults. BMC Endocrine Disorders 13:44.

NGSP (2010) HbA1c and Estimated Average Glucose (eAG), Harmonizing, HbA1c testing: A better A1c test means better diabetic care. National Institutes of Diabetes and Digestive and Kidney Diseases, 1UC4DK096587-01.

Pani, L.N., Korenda, L., Meigs, J.B., Driver, C., Chamany, S., Fox, C.S., Sullivan, L., D’Agostino, R.B. \& Nathan, D.M. (2008) Effect of aging on A1C levels in individuals without diabetes: evidence from the Framingham Offspring Study and the National Health and Nutrition Examination Survey 2001- 2004. Diabetes Care 10, 1991-1996. 
Raja Reddy, P., Reethesh, R.P. \& Mahesh, V. (2013) The association between estimated average glucose levels and fasting plasma glucose levels in a rural tertiary care centre. Global Journal of Medicine and Public Health 2(1).

Rohlfing, C.L., Wiedmeyer, H., Little, R.R., England, J.D., Tennill, A. \& Goldstein, D.E. (2002) Defining the Relationship Between Plasma Glucose and HbA1c: Analysis of Glucose Profiles and $\mathrm{HbA}_{1 c}$ in the Diabetes Control and Complications Trial. Diabetes Care 25 (2).

Roszyk, L., Faye, B., Sapin, V., Somda, F. \& Tauveron, I. (2007) Glycated haemoglobin (HbA1c): today and tomorrow. Annals of Endocrinology (Paris) 68, 357-365.

Sacks, D.B., Bruns, D.E., Goldstein, D.E., Maclaren, N.K., McDonald, J.M. \& Parrott, M. (2002) Guidelines and recommendations for laboratory analysis in the diagnosis and management of diabetes mellitus. Clinical Chemistry 48, 436-472.

Saiedullah, M., Begum, S., Shermin, S., Rahman, M.R. \& Khan, M.A.H. (2011) Relationship of glycosylated haemoglobin with fasting and postprandial plasma glucose in nondiabetic, pre-diabetic and newly diagnosed diabetic subjects. Bangladesh Medical Journal 40 (4).

Sidorenkov, G., Haaijer-Ruskamp, F.M., de Zeeuw, D. \& Denig, P. (2011) A longitudinal study examining adherence to guidelines in diabetes care according to different definitions of adequacy and timeliness. PLoS One 6 (9): e24278.

Turk, Z., Mesić, R. \& Benko, B. (1998) Comparison of advanced glycation endproducts on haemoglobin (Hb-AGE) and haemoglobin A1c for the assessment of diabetic control. assessment of diabetic control. International Journal of Clinical Chemistry 277, 159-170.

WHO (2007) WHO STEPS instrument (version 3): The WHO STEPwise approach to chronic disease risk factor surveillance (STEPS): WHO, 20 Avenue Appia, 1211 Geneva. 27, Switzerland: Available at http://www.who.int/chp/steps/en [Accessed on 24th June 2014].

Wiener, K. \& Roberts, N.B. (1999) Age does not influence levels of $\mathrm{HbA}_{1 \mathrm{c}}$ in normal subject. International Journal of Medicine 92, 169-173.

Wiwanitkit, V. (2011) Energy fluctuation in glycosylated end product formation: a new explanation on pathogenesis for complication in poorly controlled diabetic patient. Advance Laboratory Medicine International 1: 6-10.

Wiwanitkit, V. (2012) Retrospective meta-analysis study. Correlation between hemoglobin a1c level and fasting blood glucose level: a summary on the reports in the setting with high prevalence of hemoglobin disorder scientific. Journal of the Faculty of Medicine in Niš 29, 89-92. 